\title{
Concrete Mix Design for Service Life of RC Structures under Carbonation Using Genetic Algorithm
}

\author{
Seung-Jun Kwon, ${ }^{1}$ Byung Jae Lee, ${ }^{2}$ and Yun Yong Kim ${ }^{2}$ \\ ${ }^{1}$ Department of Civil and Environmental Engineering, Hannam University, 133 Ojeong-dong, Daedeok-gu, \\ Daejeon 306-791, Republic of Korea \\ ${ }^{2}$ Department of Civil Engineering, Chungnam National University, 99 Daehak-ro, Yuseong-gu, Daejeon 305-764, Republic of Korea
}

Correspondence should be addressed to Yun Yong Kim; yunkim@cnu.ac.kr

Received 15 October 2013; Revised 18 December 2013; Accepted 18 December 2013; Published 18 February 2014

Academic Editor: Amit Bandyopadhyay

Copyright (C) 2014 Seung-Jun Kwon et al. This is an open access article distributed under the Creative Commons Attribution License, which permits unrestricted use, distribution, and reproduction in any medium, provided the original work is properly cited.

\begin{abstract}
Steel corrosion in reinforced concrete (RC) structure is such a critical problem to structural safety that many researches have been performed for maintaining required performance during intended service life. This paper is for a numerical technique for obtaining optimum concrete mix proportions through genetic algorithm (GA) for RC structures under carbonation which is considered as a serious deterioration in underground sites and big cities. For this study, mix proportions and $\mathrm{CO}_{2}$ diffusion coefficients are analyzed through the previous studies, and then the fitness function of $\mathrm{CO}_{2}$ diffusion coefficient is derived through regression analysis. The fitness function from 69 test results includes 5 variables of mix proportions such as w/c (water to cement) ratio, cement content, sand content percentage, coarse aggregate content, and R.H. (relative humidity). Through GA technique, simulated mix proportions are obtained for 12 cases of verification and they show reasonable results with average relative error of $4.6 \%$. Assuming intended service life and design parameters, intended $\mathrm{CO}_{2}$ diffusion coefficients and cement contents are determined and then related mix proportions are simulated. The proposed technique can provide initial concrete mix proportions which satisfy service life under carbonation.
\end{abstract}

\section{Introduction}

$\mathrm{CO}_{2}$ concentration is increasing due to fossil energy consumption and this causes more carbonation damage to RC structures $[1,2]$. Carbonation means that $\mathrm{pH}$ in pore water drops to about 10.5 due to intrusion of exterior $\mathrm{CO}_{2}[3]$ and consumption of $\mathrm{CaOH}_{2}$. In carbonated concrete, embedded steel is easily corroded. It is so critical deterioration phenomenon that it should be considered in durability design for underground RC structures or those in metropolitan cities which have high $\mathrm{CO}_{2}$ concentration.

With higher $\mathrm{CO}_{2}$ concentration, carbonation depth increases but this can be comparatively controlled by a design of concrete mix proportions. The influencing parameters on carbonation are reported to be type of cement, unit content of cement, type of aggregate, and so on [2]. Semiempirical prediction techniques, so-called mesolevel, have been proposed and they are still utilized for the sake of simple and practical application $[4,5]$. Carbonation mechanism can be explained as diffusion of $\mathrm{CO}_{2}$ and carbonatable materials like calcium hydroxide $\left(\mathrm{Ca}(\mathrm{OH})_{2}\right)$ and calcium silicate hydrates (C-H-S). $\mathrm{CO}_{2}$ diffusion represents how fast $\mathrm{CO}_{2}$ gas (or liquid) intrudes into concrete, so that concrete with high $\mathrm{CO}_{2}$ diffusion coefficient allows rapid carbonation. From the defensive point of view for carbonation, concrete with larger carbonatable materials can keep high alkali so long as they are not fully consumed due to carbonation reaction. From 1980, several physico-chemo carbonation models have been proposed. They are all constructed by both modeling on diffusion coefficient based on pore structure and modeling on carbonic reaction based on dissociation of carbonatable materials $[3,6-8]$. Carbonation modeling for cracked and joint concrete is similarly performed considering the larger $\mathrm{CO}_{2}$ intrusion due to crack effect and cold joint effect [9-12]. Recently, carbonation prediction techniques are proposed through experimentally measuring $\mathrm{CO}_{2}$ diffusion coefficient 
[13-15] and numerically obtaining $\mathrm{CO}_{2}$ diffusion coefficient through neural network algorithm [16].

If environmental conditions like $\mathrm{CO}_{2}$ concentration, temperature, and R.H. are quantitatively evaluated, intended carbonation depth in design stage can be determined considering design cover depth and intended service life. Provided that various mix proportions and the related $\mathrm{CO}_{2}$ diffusion coefficients are experimentally given, intended $\mathrm{CO}_{2}$ diffusion coefficient satisfying the intended service life can be obtained. Then mix proportions satisfying the intended $\mathrm{CO}_{2}$ diffusion coefficient can be obtained through optimization technique as well.

GA (generic algorithm) technique is a representative optimization technique and widely utilized in civil engineering. Through reverse analysis, the parameters which satisfy the fitness function can be derived so that application of GA has been extended. For the application of GA to concrete researches, mix proportion optimizations are performed only for strength prediction in HPC (high performance concrete) $[17,18]$. With regard to durability design for service life, very limited research has been performed for chloride attack [19]. For carbonation, optimization of mix proportions has not been carried out so far.

In this paper, $\mathrm{CO}_{2}$ diffusion coefficients and the related mix proportions are investigated. Based on 69 mix proportions and diffusion coefficients; the fitness function for $\mathrm{CO}_{2}$ is derived through MATLAB with parameters of mixing variables ( $\mathrm{w} / \mathrm{c}$ ratio, unit content of cement, and fine and coarse aggregates) and exterior variables (R.H.). Through comparison with the previous test results, the applicability of GA technique for optimum mix proportions is verified. Assuming the intended service life and environmental conditions, the intended $\mathrm{CO}_{2}$ diffusion coefficient is calculated. Finally, the mix proportions which satisfy the intended $\mathrm{CO}_{2}$ diffusion coefficient are derived through GA technique. This technique can be utilized for performance-based concrete mix design. The techniques for carbonation prediction and optimization of mix proportions are dealt with in this paper.

\section{Background of GA and Influencing Parameters on Carbonation}

2.1. Overview of GA. Unlike conventional search technique, GA technique constructs arbitrary solutions in initial group, and then the fittest solution is derived through modification of the solutions. GA technique is mainly utilized in the field of mechanical and electrical engineering and recently applied to civil engineering such as design optimization for structures, line network analysis, and concrete mix design for strength. This technique can provide more accurate results than other algorithms having many local solutions [20,21]. GA technique starts with an initial set of random solutions called population. Each individual in the population is called a chromosome, which represents a solution to the problem at hand. The evolution operator simulates Darwinian evolution process to create population from generation to generation. The availability of genetic algorithm depends on its ability to keep existing parts of solution, which have a positive effect on

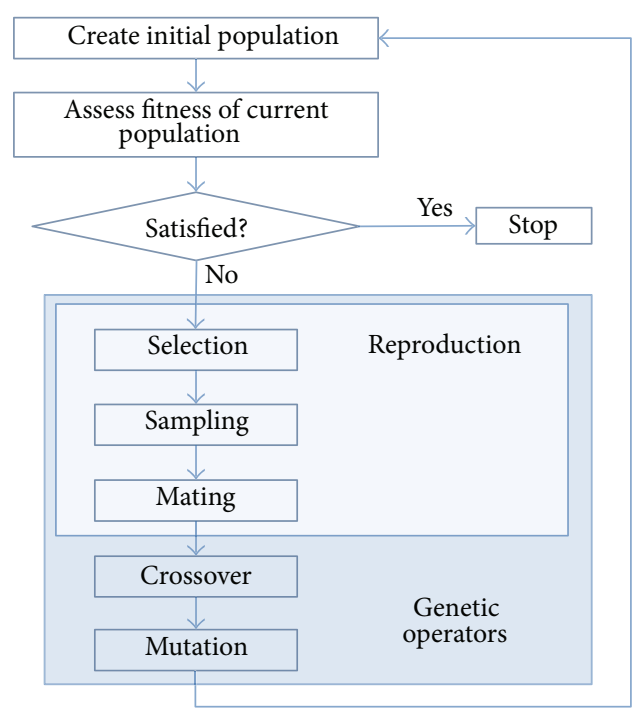

Figure 1: Genetic algorithm process [29].

the outcome, and proceed with optimizing the nonoptimal part. The transition rules which combine and change those samples for improving the solutions are probabilistic and not deterministic. This enables genetic algorithm to reach a global optimum without being fixed in local optima [18]. In the selection stage, GA fundamentally starts from Darwinian natural selection and the initial individuals are selected in this process. Selection provides the driving force in genetic algorithm, and selection pressure is critical in it. The selection directs genetic algorithm search toward promising regions in the search space [18]. The second stage, crossover is the most important genetic operator in which the bit-strings of two (or more) parents are cut into two (or more) pieces and the parts of bit-string are crossed over. The point where the parents are cut is randomly determined. Through the crossover operator, a new child population has been created using inherited values from the parent population. Mutation operator is used to insert new information into the new population, preventing GA from getting stuck in certain regions of the parameter space [18]. Mutation consists of making slight changes in parameters of child population after they have been generated by crossover. More detailed information on GA can be found in many researches [17-21]. The process of GA is presented in Figure 1.

\subsection{Study of Carbonation Parameters and Prediction Tech-} niques. Influencing parameters on carbonation can be classified into two groups. One is for external parameters regarding environmental conditions and the other is for internal parameters regarding diffusion coefficient and carbonatable materials. Considering these parameters, many carbonation prediction techniques have been proposed in semiempirical form. These equations assume that carbonation depth is proportional to square root of exposed time. This assumption was verified through experiments, field investigations $[1,2,9$, $22]$, and analytical solution [6, 23]. In Table 1, carbonation parameters are summarized. Conventional techniques for carbonation prediction are listed in Table $2[1,2]$. 
TABLE 1: Influencing parameter on carbonation behavior.

\begin{tabular}{|c|c|c|}
\hline \multirow{6}{*}{$\begin{array}{l}\text { Internal } \\
\text { parameter } \\
\text { (mixture) }\end{array}$} & $\begin{array}{l}\text { Low } \mathrm{w} / \mathrm{c} \text { and large unit } \\
\text { cement amount }\end{array}$ & $\begin{array}{l}\text { (i) Holding } \mathrm{pH} \text { in alkali through producing large } \\
\text { amount of hydration of } \mathrm{CSH} \text { and } \mathrm{Ca}(\mathrm{OH})_{2} \\
\text { (ii) Low } \mathrm{CO}_{2} \text { diffusion through dense pore structure }\end{array}$ \\
\hline & Aggregate & $\mathrm{CO}_{2}$ intrusion through artificial light weight aggregate \\
\hline & Mineral admixture & $\begin{array}{l}\text { (i) Small amount of } \mathrm{Ca}(\mathrm{OH})_{2} \text { due to pozzolanic } \\
\text { reaction and latent hydraulic reaction }\end{array}$ \\
\hline & (slag and fly ash) & (ii) Low diffusion coefficient of $\mathrm{CO}_{2}$ \\
\hline & Mixed chloride content & $\begin{array}{l}\text { Rapid carbonic reaction due to high } \mathrm{pH} \text { from ion } \\
\text { dissociation }\end{array}$ \\
\hline & Alkali & $\begin{array}{l}\text { (i) Rapid carbonic reaction due to high alkali cement } \\
\text { (ii) Residual metallic oxide }\left(\mathrm{K}_{2} \mathrm{O}, \mathrm{Na}_{2} \mathrm{O}\right)\end{array}$ \\
\hline \multirow{5}{*}{$\begin{array}{l}\text { External } \\
\text { parameter }\end{array}$} & $\mathrm{CO}_{2}$ concentration & $\begin{array}{l}\text { Rapid carbonation through higher concentration of } \\
\mathrm{CO}_{2}\end{array}$ \\
\hline & Temp. & $\begin{array}{l}\text { Increasing activity energy due to high temperature } \\
\text { (Arrhenius law) }\end{array}$ \\
\hline & R.H. & $\begin{array}{l}\text { (i) Decreasing carbonation in low R.H. due to } \\
\text { insufficient } \mathrm{H}_{2} \mathrm{O}\end{array}$ \\
\hline & & $\begin{array}{l}\text { (ii) Decreasing carbonation in high R.H. due to low } \\
\mathrm{CO}_{2} \text { diffusion }\end{array}$ \\
\hline & Induced chloride ion & $\begin{array}{l}\text { Rapid carbonation due to dissociated chloride ion } \\
\text { (cation) }\end{array}$ \\
\hline
\end{tabular}

TABLE 2: Semiempirical equations for carbonation process.

\begin{tabular}{lc}
\hline Researcher & Equations \\
\hline Syrayama & $t=\alpha \beta \gamma \delta \varepsilon \frac{5000 C^{2}}{(x-38)^{2}}$ \\
$C:$ carbonation depth, $x:$ w/c ratio
\end{tabular}

$\alpha, \beta, \gamma, \delta, \varepsilon$ : factors for admixtures, cement type, exposure condition, and so forth

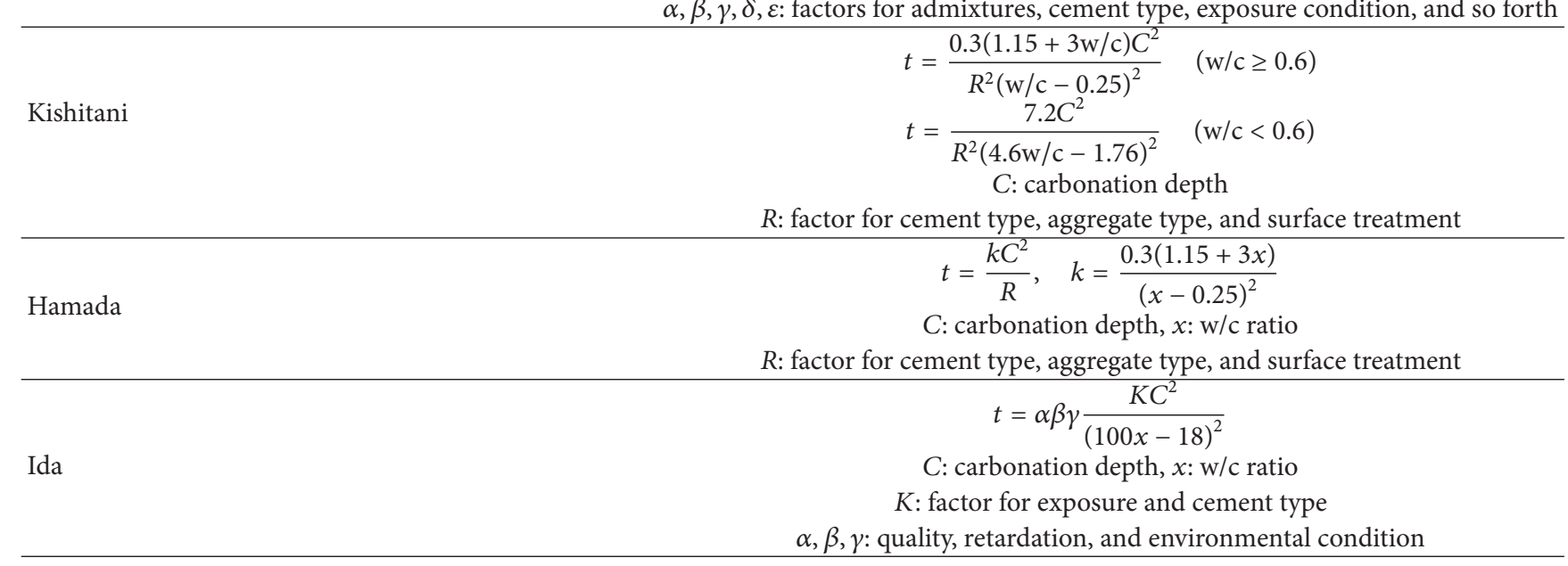

The flowchart for this study is shown in Figure 2. Through this study, fitness function for diffusion coefficient, intended diffusion coefficient for service life, and mix proportions satisfying intended diffusion coefficient are derived using GA technique.

\section{Concrete Mix Optimization Using GA}

\subsection{Fitness Function for Diffusion Coefficient}

3.1.1. Previous Test for Diffusion of $\mathrm{CO}_{2}[14,16]$. For the derivation of fitness function, the previous test results are adopted. In the test, $\mathrm{CO}_{2}$ diffusion coefficients were measured through diffusion cell. Three different mix conditions and 4 different R.H. were considered [14]. So far, several researches have been reported for the test of $\mathrm{CO}_{2}$ diffusion coefficients; however, they are not for concrete but for cement mortar or cement paste $[6,13]$. Very limited cases are reported for $\mathrm{CO}_{2}$ diffusion coefficient in concrete. In Table 3, the procedures for the adopted test are summarized. Mix proportions and cement properties are listed in Table 4. The test adopted in this paper covers only OPC (Ordinary Portland Cement, type I) concrete since concrete with mineral admixtures has different carbonation behavior due to the decreased diffusion coefficient and pozzolan reaction $[3,7]$. 


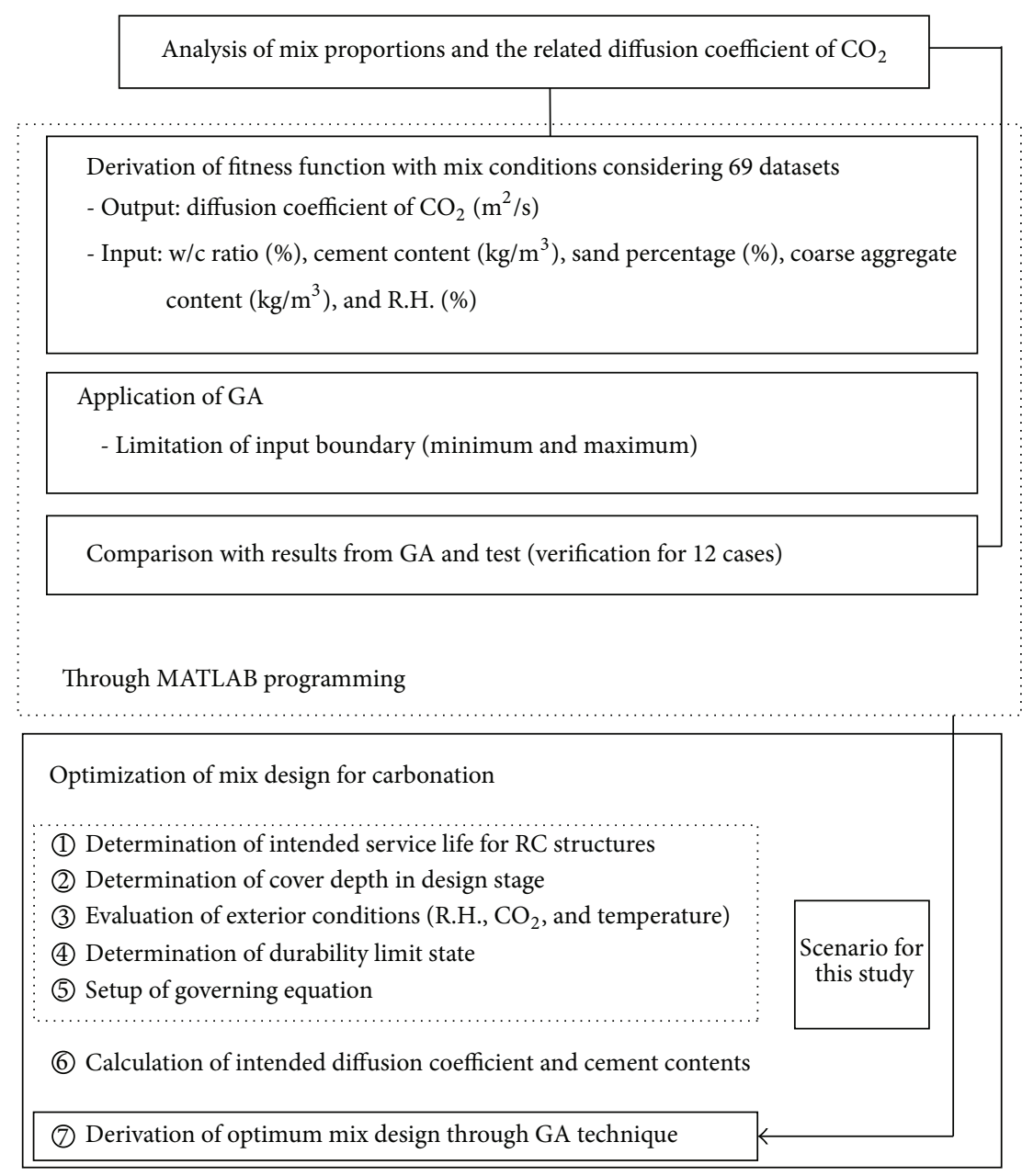

FIGURE 2: Flowchart for this concrete mix optimization.

TABle 3: Summary of test setup [14].

\section{Steps}

(a) Installation of test equipment in room $\left(20^{\circ} \mathrm{C}\right)$

(b) Measurement of concrete sample thickness and diameter

(c) Installation of sample (concrete disk) in cell

(d) Applying $\mathrm{N}_{2}$ gas and $\mathrm{CO}_{2}$ gas to different cells with same pressure

(e) Measurement of $\mathrm{CO}_{2}$ concentration when $\mathrm{CO}_{2}$ concentration in $\mathrm{N}_{2}$ gas keeps constant (steady state)

$D_{\mathrm{CO}_{2}}=\frac{Q f_{\mathrm{CO}_{2}} L}{\left(1-f_{\mathrm{CO}_{2}}\right) A}$

$D_{\mathrm{CO}_{2}}$ : diffusion coefficient of $\mathrm{CO}_{2}$; Q: flow rate of gas

$f_{\mathrm{CO}_{2}}$ : mol fraction in $\mathrm{N}_{2}+\mathrm{CO}_{2} ; L$ : thickness of disk; $A$ : area of disk

3.1.2. Derivation of Fitness Function. The adopted test was performed considering 4 different R.H. as 10\%, 45\%, 75\%, and $90 \%$. In order to obtain more reasonable fitness function, several previous test results $[15,24,25]$ are considered. Carbonation process is very sensitive to R.H. since concrete
TABle 4: Mix proportions for $\mathrm{CO}_{2}$ diffusion measurement [14].

(a)

\begin{tabular}{lccccc}
\hline Case & $\begin{array}{r}\mathrm{w} / \mathrm{c} \\
(\%)\end{array}$ & $\begin{array}{c}\text { Cement } \\
\left(\mathrm{kg} / \mathrm{m}^{3}\right)\end{array}$ & $\begin{array}{c}\text { Water } \\
\left(\mathrm{kg} / \mathrm{m}^{3}\right)\end{array}$ & $\begin{array}{c}\text { Sand } \\
\left(\mathrm{kg} / \mathrm{m}^{3}\right)\end{array}$ & $\begin{array}{c}\text { Coarse } \\
\text { aggregate } \\
\left(\mathrm{kg} / \mathrm{m}^{3}\right)\end{array}$ \\
\hline 1 & 42 & 425 & 179 & 714 & 895 \\
2 & 50 & 315 & 158 & 748 & 1,076 \\
3 & 58 & 277 & 161 & 726 & 1,117 \\
\hline
\end{tabular}

(b)

\begin{tabular}{lccc}
\hline \multicolumn{4}{c}{ Aggregate properties } \\
Type & Specific gravity & Absorption (\%) & Fineness modulus \\
\hline Fine & 2.56 & 2.18 & 2.85 \\
Coarse & 2.60 & 0.94 & 6.51 \\
\hline
\end{tabular}

with high saturation allows active carbonation reaction but low diffusion of $\mathrm{CO}_{2}$, and concrete with low saturation allows high diffusion of $\mathrm{CO}_{2}$ but it has little $\mathrm{H}_{2} \mathrm{O}$ for carbonic reaction. With higher R.H. and lower w/c ratio, $\mathrm{CO}_{2}$ diffusion coefficients decrease as in Figure 3. In Figure 3, several results 


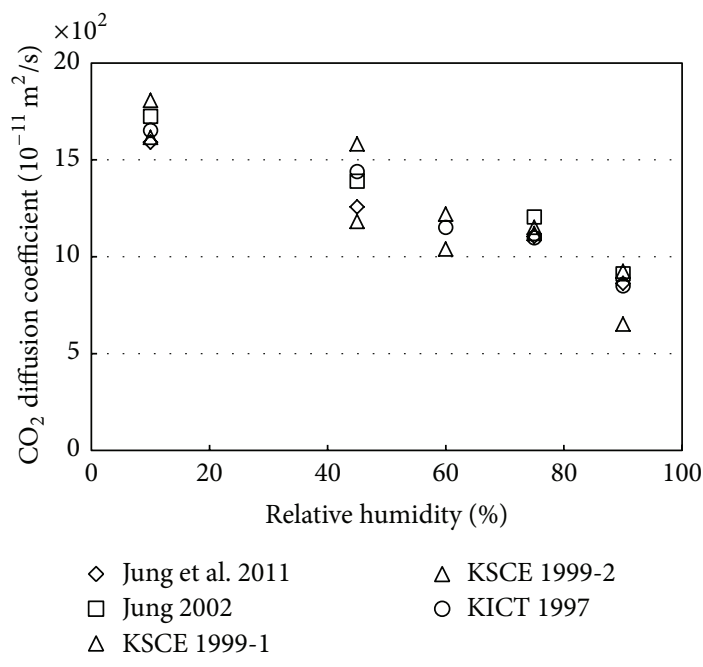

(a) $\mathrm{w} / \mathrm{c} 42 \%$

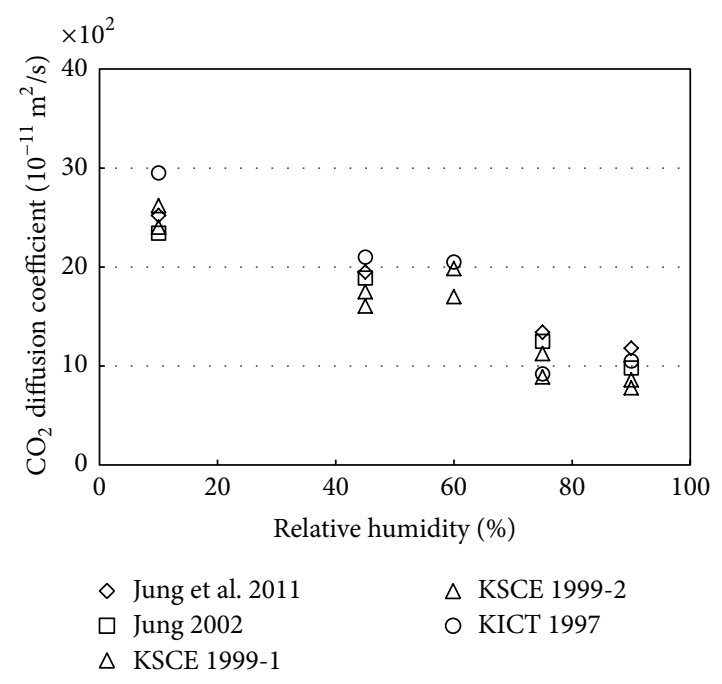

(b) $\mathrm{w} / \mathrm{c} 50 \%$

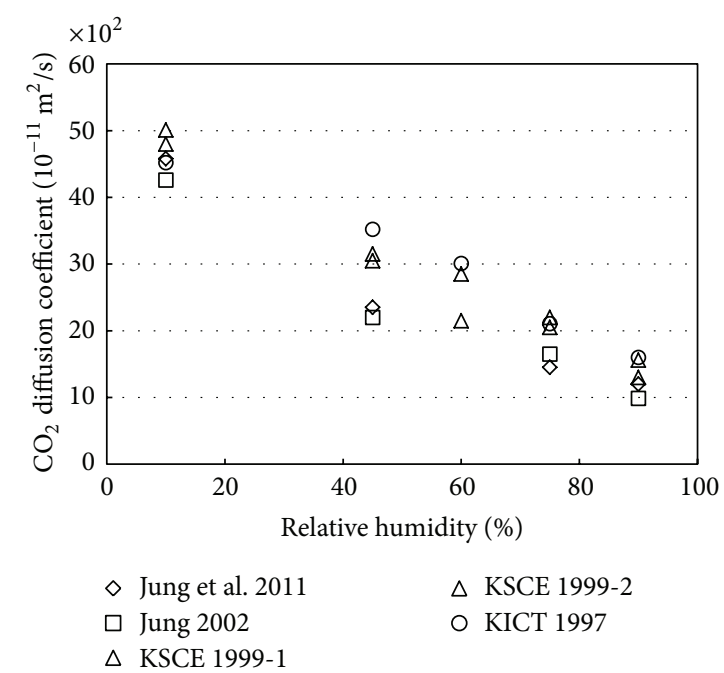

(c) $\mathrm{w} / \mathrm{c} 58 \%$

Figure 3: $\mathrm{CO}_{2}$ diffusion coefficients with w/c ratios and R.H.

TABLE 5: Variables for fitness function.

\begin{tabular}{lccccccc}
\hline Type & w/c $(\%)$ & $C\left(\mathrm{~kg} / \mathrm{m}^{3}\right)$ & S/a $(\%)$ & $G\left(\mathrm{~kg} / \mathrm{m}^{3}\right)$ & R.H. $\left(\mathrm{kg} / \mathrm{m}^{3}\right)$ & $a$ and $b$ & Constant \\
\hline Max & 100 & 0 & 10 & 10 & 30 & 1 & 200,000 \\
Min & -100 & -100 & -10 & -10 & -30 & -1 & 0 \\
\hline
\end{tabular}

$[25,26]$ are obtained from reverse analysis based on measured carbonation depth with constant R.H.

For the relation with mix proportions and $\mathrm{CO}_{2}$ diffusion coefficient, fitness function with mix components should be obtained. In the previous researches, fitness function for strength was derived through linear multiregression curve, which contained the variables of mix components like w/c ratio and unit amount of cement [18]. Unlike the fitness function for strength, R.H. is very critical to $\mathrm{CO}_{2}$ diffusion coefficient, so that both mix components (w/c ratio, content of cement, sand ratio, and content of coarse aggregate) and
R.H. are considered as variables in the fitness function in this analysis.

In the optimization technique, many local solutions can be obtained. For avoiding convergence to local solution, initial variables (starting variables) and wide ranges for each solution are necessary. Even wide ranges of solutions are considered, local solutions may be obtained because of the initial variables in conventional optimization techniques, so that GA technique is preferred for searching solution in overall ranges. The variables and the related ranges are listed in Table 5. 


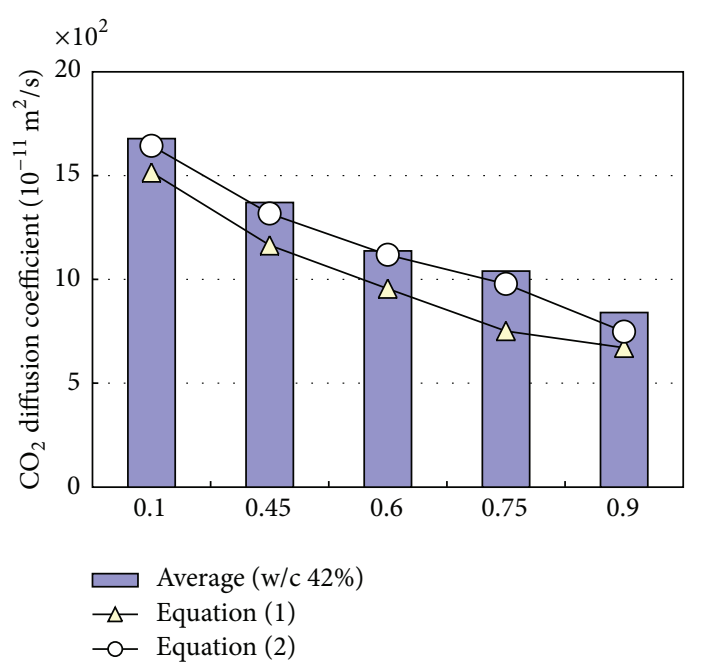

(a) $\mathrm{w} / \mathrm{c} 42 \%$

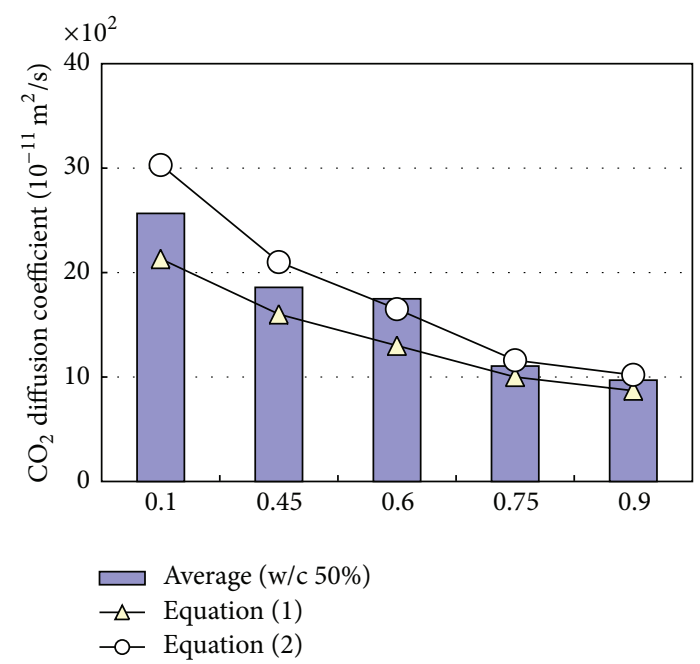

(b) $\mathrm{w} / \mathrm{c} 50 \%$

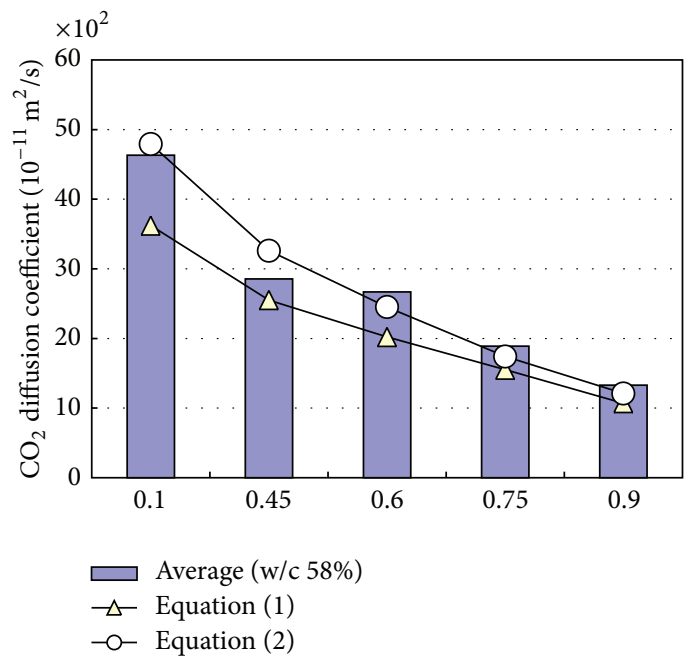

(c) $\mathrm{w} / \mathrm{c} 58 \%$

FIGURE 4: Test and simulated results for diffusion coefficient.

TABLE 6: Variables and constants in regression analysis.

\begin{tabular}{ccccccc}
\hline & $I$ & $A$ & $B$ & $C$ & $D$ & $E$ \\
\hline Equation (1) & 1018.56 & 16.08 & -1.42 & 2.75 & 0.60 & -9.75 \\
Equation (2) & $15,427.82$ & 49.562 & -29.60 & 5.48 & -4.42 & 9.79 \\
& \multicolumn{5}{c}{$a:-0.005825 ; b: 0.7542$} \\
\hline
\end{tabular}

$\mathrm{w} / \mathrm{c}: \mathrm{w} / \mathrm{c}$ ratio (\%); C: cement content $\left(\mathrm{kg} / \mathrm{m}^{3}\right) ; \mathrm{S} / \mathrm{a}$ : sand percentage (sand/total aggregate) (\%); Agg: coarse aggregate content $\left(\mathrm{kg} / \mathrm{m}^{3}\right) ; \mathrm{R} . \mathrm{H}$ : relative humidity (\%); I: Intersection (constant).

With larger unit content of cement, diffusion coefficient decreases, so that $C$ in Table 5 is set to have below zero. w/c ratio is assumed to have a range of $-100 \sim 100$. S/a (sand to total aggregate) and $G$ have relatively small effect on $\mathrm{CO}_{2}$ diffusion, so that they are assumed to have small range of $-10 \sim 10 . \mathrm{CO}_{2}$ diffusion coefficient is much dependent on R.H., so that the range of R.H. is assumed as $-30 \sim 30$.

Typical multiregression analysis is shown in (1). In (2), additional term for the consideration of R.H. is added. Averages of relative error are evaluated to be $17.3 \%$ from (1) and 7.6\% from (2), respectively. The results of multiregression curves are listed in Table 6 . For the derivation of constant in (1) and (2), GA technique is utilized. Consider

$$
\begin{aligned}
D_{\mathrm{CO}_{2}}= & I+A\left(\frac{\mathrm{w}}{\mathrm{c}}\right)+B(C) \\
& +C\left(\frac{\mathrm{S}}{\mathrm{a}}\right)+D(\mathrm{Agg})+E(\mathrm{RH}), \\
D_{\mathrm{CO}_{2}}= & {\left[I+A\left(\frac{\mathrm{w}}{\mathrm{c}}\right)+B(C)+C\left(\frac{\mathrm{S}}{\mathrm{a}}\right)\right.} \\
& +D(\mathrm{Agg})+E(\mathrm{RH})](a \mathrm{RH}+b) .
\end{aligned}
$$

In Figure 4, the results of regression analysis ((1) and (2)) and test results (averages) are compared. As shown in Figure 4, when (1) is selected, it provides a big error for the case of high w/c ratio (w/c 58\%), so that (2) is selected for fitness function for this study. For the case of w/c 58\%, (1) 


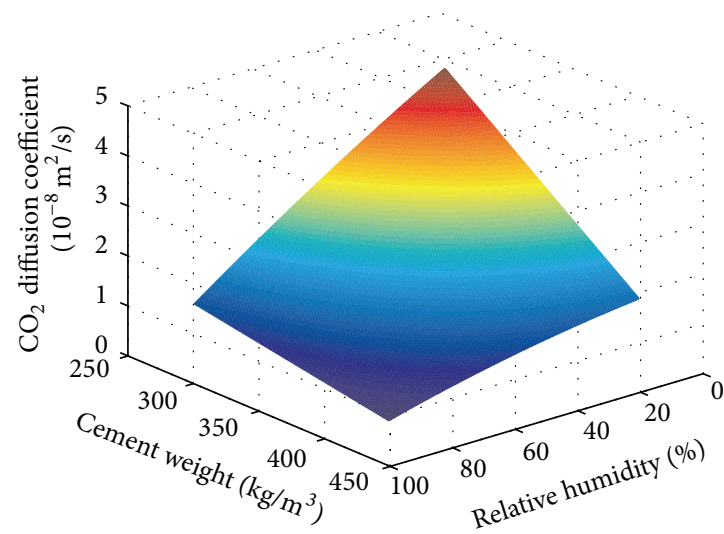

(a) Case 1: w/c 42\%

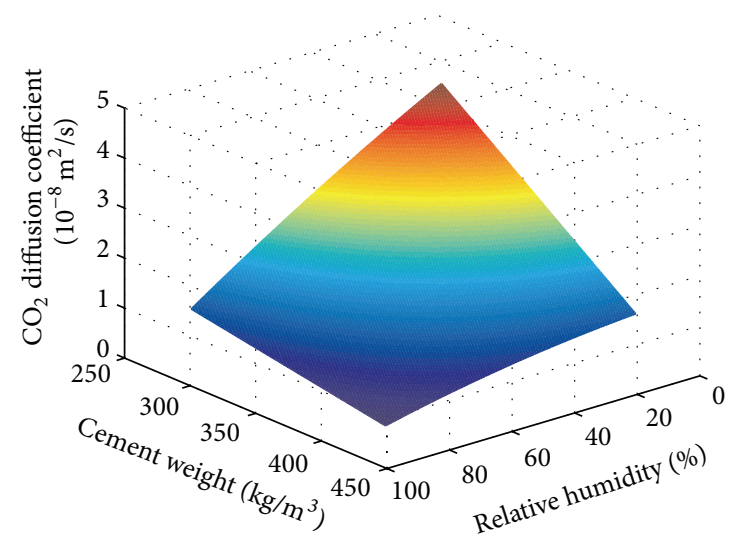

(b) Case 2: w/c 50\%

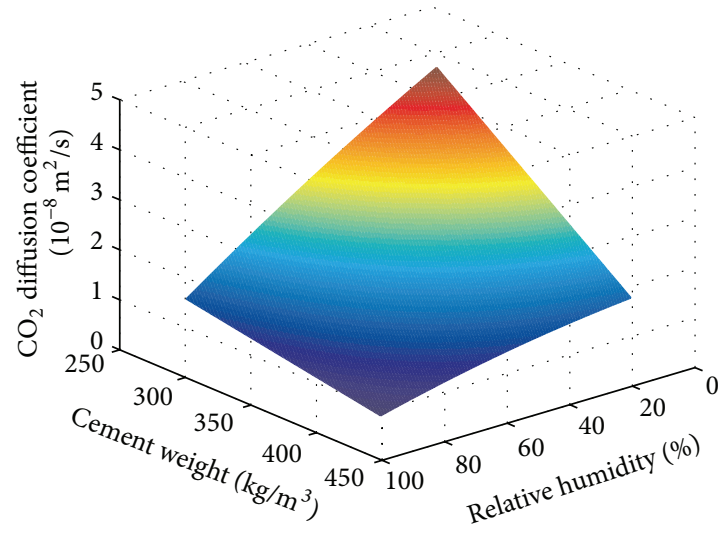

(c) Case 3: w/c 58\%

FIGURE 5: Diffusion coefficient contour with cement content and relative humidity.

shows the relative error range of $10.6 \sim 24.3 \%$ but (2) shows $3.3 \sim 14.2 \%$. If a better fitness curve can be defined through nonlinear regression analysis, it would provide the more reasonable mix proportions based on the test dataset.

$\mathrm{CO}_{2}$ diffusion coefficients are strongly dependent on mix proportions. The contours are shown in Figure 5. Case 1 represents w/c $42 \%$ in Table 4, where unit cement content is changed from $277 \mathrm{~kg} / \mathrm{m}^{3}$ to $425 \mathrm{~kg} / \mathrm{m}^{3}$ and R.H. is changed from $10 \%$ to $90 \%$. Cases 2 and 3 show the simulations of $\mathrm{CO}_{2}$ diffusion coefficient in w/c 50\% and 58\%, respectively. With larger cement content and higher R.H., $\mathrm{CO}_{2}$ diffusion coefficients decrease in every case.

\subsection{Evaluation of GA Applicability to Generating Mix Pro-} portion. In order to evaluate the applicability of GA, verification is performed for 3 different cases (w/c $42 \%$ with R.H. $10 \%$, w/c 50\% with R.H. 75\%, and w/c 58\% with R.H. 90\%). Population size is set as 20 and the number of generation is set as 10,000 for avoiding early convergence. For formation of 1st generation, uniform function is adopted. For parent selection for next generation, stochastic uniform function is utilized and two superior chromosomes are transferred to next generation. Crossover function of two-point is adopted and normal distribution is considered for mutation operator with mutation ratio of 0.8 .

Determination of up/down boundary conditions is important to obtain each mix component and this needs user's experience. The range of boundary conditions, obtained mix components through GA, and the range of relative errors are listed in Table 7. Output results are mix component and $\mathrm{CO}_{2}$ diffusion coefficient. R.H. is set to fix since it can be known from exterior condition. The fixed R.H. is made through letting up/down boundaries have the same R.H. value.

For 12 data [14], the comparison with test and simulated results from GA are shown in Figure 6(a) with regard to $\mathrm{CO}_{2}$ diffusion coefficient, which shows a reasonable agreement. In Figure 6(b), the comparison of relative errors is shown for 12 cases and the average relative error of each component is shown in Figure 6(c). The processes of searching the optimum solutions are plotted in the case of w/c $42 \%$ with R.H. $10 \%$ from Figure 7(a) to Figure 7(e).

As listed in Table 7, this technique reasonably estimates the $\mathrm{CO}_{2}$ diffusion coefficients and mix proportions with $-5.0 \sim 10.1 \%$ of relative errors. 
TABLE 7: Comparison with results from test and simulation from GA.

\begin{tabular}{|c|c|c|c|c|c|c|}
\hline $\mathrm{w} / \mathrm{c}(\%)$ & Diffusion coefficient $\left(10^{-11} \mathrm{~m}^{2} / \mathrm{sec}\right)$ & w/c (\%) & R.H. (\%) & Cement $\left(\mathrm{kg} / \mathrm{m}^{3}\right)$ & S/a (\%) & Coarse aggregate $\left(\mathrm{kg} / \mathrm{m}^{3}\right)$ \\
\hline 42 & 1574 & 42.0 & 10 & 425 & 44.4 & 895 \\
\hline Input range & - & $40-45$ & $10-10$ & $400-450$ & $39-45$ & $800-895$ \\
\hline Result from GA & 1580.5 & 41.5 & - & 419.2 & 41.8 & 874.5 \\
\hline Relative error (\%) & 0.4 & -1.2 & & -1.4 & -5.9 & -2.3 \\
\hline 42 & 1257 & 42.0 & 45 & 425 & 44.4 & 895 \\
\hline Input range & - & $40-45$ & $45-45$ & $400-450$ & $39-45$ & $800-895$ \\
\hline Result from GA & 1194.2 & 42.1 & - & 420.8 & 42.2 & 869.7 \\
\hline Relative error (\%) & -5.0 & 0.24 & & 0.0 & -5.0 & -2.9 \\
\hline 42 & 1105 & 42.0 & 75 & 425 & 44.4 & 895 \\
\hline Input range & - & $40-45$ & $75-75$ & $400-450$ & $39-45$ & $800-895$ \\
\hline Result from GA & 1088.4 & 42.2 & - & 421.2 & 42.0 & 882.1 \\
\hline Relative error (\%) & -1.5 & 0.5 & & -0.9 & -5.4 & -1.4 \\
\hline 42 & 862 & 42.0 & 90 & 425 & 44.4 & 895 \\
\hline Input range & - & $40-45$ & $90-90$ & $400-450$ & $39-45$ & $800-895$ \\
\hline Result from GA & 855.2 & 41.8 & - & 426.1 & 43.2 & 887.2 \\
\hline Relative error (\%) & -0.8 & -0.5 & & 0.3 & -2.7 & -0.9 \\
\hline 50 & 2520 & 50.0 & 10 & 315 & 41.0 & 1076 \\
\hline Input range & - & $47.5-52.5$ & $10-10$ & $290-330$ & $39-45$ & $950-1100$ \\
\hline Result from GA & 2775.2 & 49.8 & - & 311.8 & 42.6 & 1085.3 \\
\hline Relative error (\%) & 10.1 & -0.4 & & -1.0 & 3.9 & 0.9 \\
\hline 50 & 1950 & 50.0 & 45 & 315 & 41.0 & 1076 \\
\hline Input range & - & $47.5-52.5$ & $45-45$ & $290-330$ & $39-45$ & $950-1100$ \\
\hline Result from GA & 2124.2 & 51.3 & - & 318.5 & 41.2 & 1092.5 \\
\hline Relative error (\%) & 8.9 & 2.6 & & 1.1 & 0.5 & 1.5 \\
\hline 50 & 1503 & 50.0 & 75 & 315 & 41.0 & 1076 \\
\hline Input range & - & $47.5-52.5$ & $75-75$ & $290-330$ & $39-45$ & $950-1100$ \\
\hline Result from GA & 1452.2 & 49.3 & - & 322.2 & 41.8 & 1044.7 \\
\hline Relative error (\%) & -3.4 & -1.4 & & 2.3 & 2.0 & -2.9 \\
\hline 50 & 1105 & 50.0 & 90 & 315 & 41.0 & 1076 \\
\hline Input range & - & $47.5-52.5$ & $90-90$ & $290-330$ & $39-45$ & $950-1100$ \\
\hline Result from GA & 1127.3 & 48.2 & - & 318.9 & 39.5 & 1068.5 \\
\hline Relative error (\%) & 4.0 & -3.6 & & 1.2 & -3.7 & -0.7 \\
\hline 58 & 4480 & 58.0 & 10 & 277 & 39.4 & 1117 \\
\hline Input range & - & $55-60$ & $10-10$ & $260-330$ & $39-45$ & $950-1300$ \\
\hline Result from GA & 4922.3 & 57.2 & - & 266.2 & 39.7 & 1204.2 \\
\hline Relative error (\%) & 9.7 & -1.4 & & -3.9 & 0.8 & 7.8 \\
\hline 58 & 2350 & 58.0 & 45 & 277 & 39.4 & 1117 \\
\hline Input range & - & $55-60$ & $45-45$ & $260-330$ & $39-45$ & $950-1300$ \\
\hline Result from GA & 2472.3 & 58.9 & - & 270.5 & 40.1 & 1200.8 \\
\hline Relative error (\%) & 5.2 & 1.6 & & -2.4 & 1.8 & 7.5 \\
\hline 58 & 1450 & 58.0 & 75 & 277 & 39.4 & 1117 \\
\hline Input range & - & $55-60$ & $75-75$ & $260-330$ & $39-45$ & $950-1300$ \\
\hline Result from GA & 1377.2 & 57.8 & - & 277.7 & 42.2 & 1208.7 \\
\hline Relative error (\%) & -5.0 & -0.3 & & 0.3 & 7.1 & 8.2 \\
\hline 58 & 1172 & 58.0 & 90 & 277 & 39.4 & 1117 \\
\hline Input range & - & $55-60$ & $90-90$ & $260-330$ & $39-45$ & $950-1300$ \\
\hline Result from GA & 1150.2 & 59.4 & - & 278.5 & 41.9 & 1187.5 \\
\hline Relative error (\%) & -0.9 & 2.4 & & 0.5 & 6.4 & 6.3 \\
\hline
\end{tabular}

The bold numbers are results from GA. 


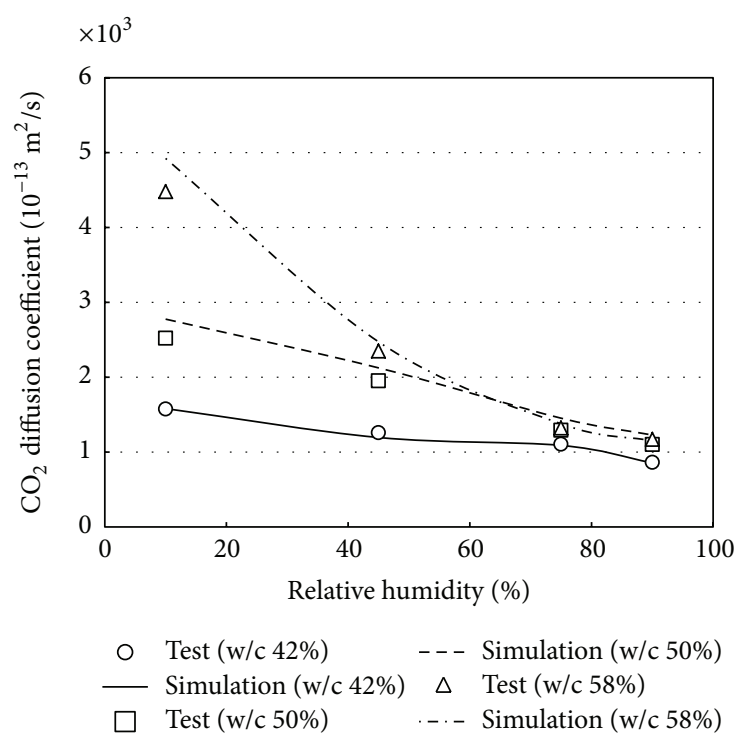

(a) Diffusion coefficient

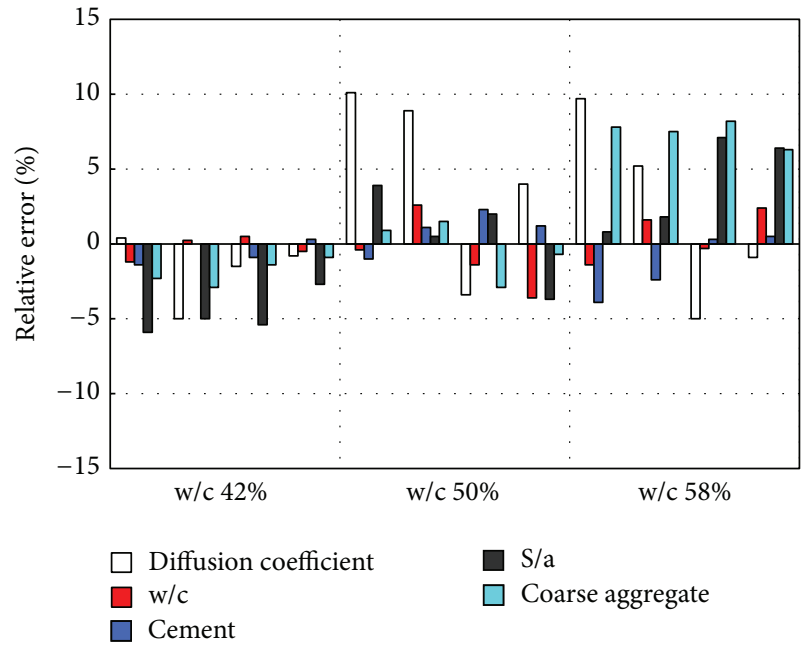

(b) Relative errors of $\mathrm{CO}_{2}$ diffusion coefficient and simulated mix components

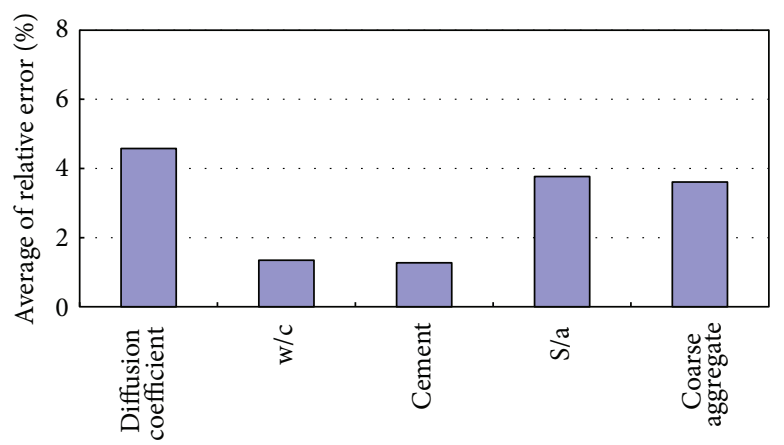

(c) Average of relative errors

FIGURE 6: Comparison with results of $\mathrm{CO}_{2}$ diffusion coefficient and relative errors.

\section{Design of Concrete Mix Proportions for Carbonation}

4.1. Scenario for Mix Design Considering Carbonation. In this section, concrete mix design is performed considering exterior condition-carbonation. The design flow is as follows:

(a) determination of intended service life,

(b) determination of design cover depth,

(c) evaluation of exterior condition,

(d) determination of durability criteria,

(e) determination of governing equation,

(f) mix optimization through GA.

If reduction factors or safety factors are considered [26, 27], conservative design can be induced. However, intended diffusion coefficient is derived assuming 1.0 of reduction and safety factor in this paper. Generally, underground site and urban area are reported to be the environments where durability design for carbonation is necessary since they have relatively high $\mathrm{CO}_{2}$ concentration and normal R.H.
(50\% 70\%). In the previous research [25], durability design for carbonation is strongly recommended over $300 \mathrm{ppm}$ of $\mathrm{CO}_{2}$ concentration. In urban cities, $\mathrm{CO}_{2}$ concentration over $350 \mathrm{ppm}$ is reported; furthermore, $\mathrm{CO}_{2}$ concentration over $650 \mathrm{ppm}$ is reported in underground sites like subway structures [25]. Several specifications [26-28] guide durability design for carbonation in urban cities and underground structures.

\subsection{Mix Design Considering Exterior Conditions and Design Parameters}

4.2.1. Scenario for Concrete Mix Design. Based on the design flow in Section 4.1, concrete mix proportions are simulated. The target structures are assumed as underground structures and two types (A and B) are considered. A structure has 75 years and B structure has 100 years for intended service life. Design cover depths are assumed as $50 \mathrm{~mm}$ for A structure and $30 \mathrm{~mm}$ for B structure. A structure has $65 \%$ of R.H. and $12.7^{\circ} \mathrm{C}$ of temperature. B structure has $75 \%$ of R.H. and $22^{\circ} \mathrm{C}$ of temperature, which are normal exterior conditions 


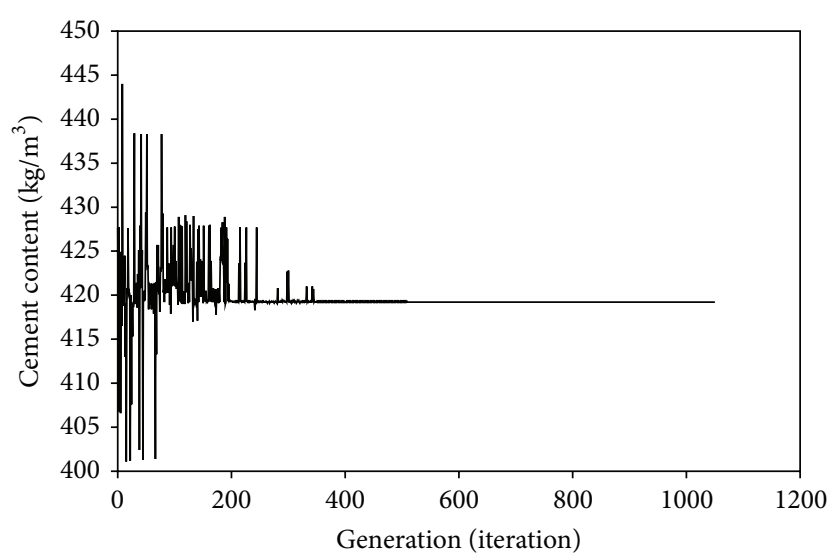

(a) Cement content

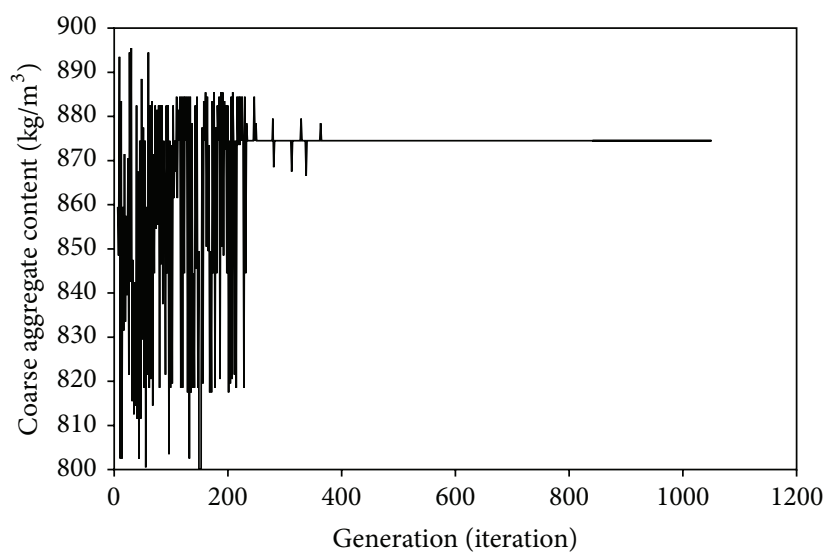

(c) Coarse aggregate content

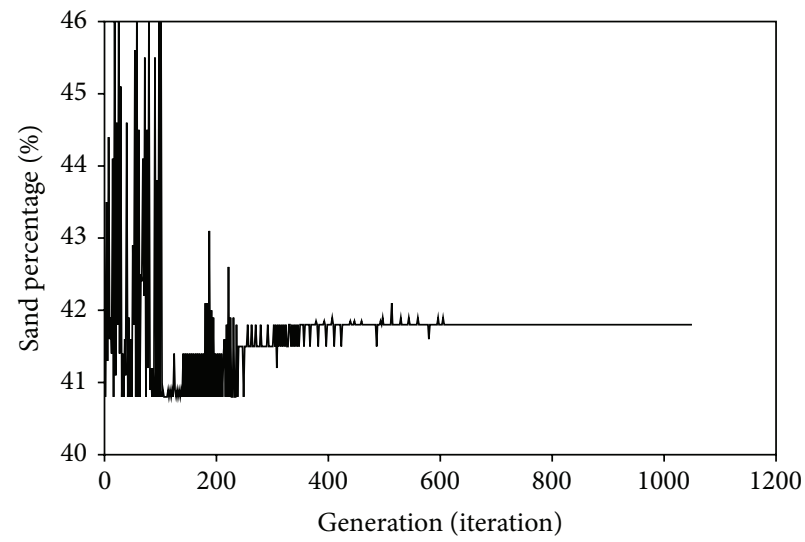

(b) Sand percentge

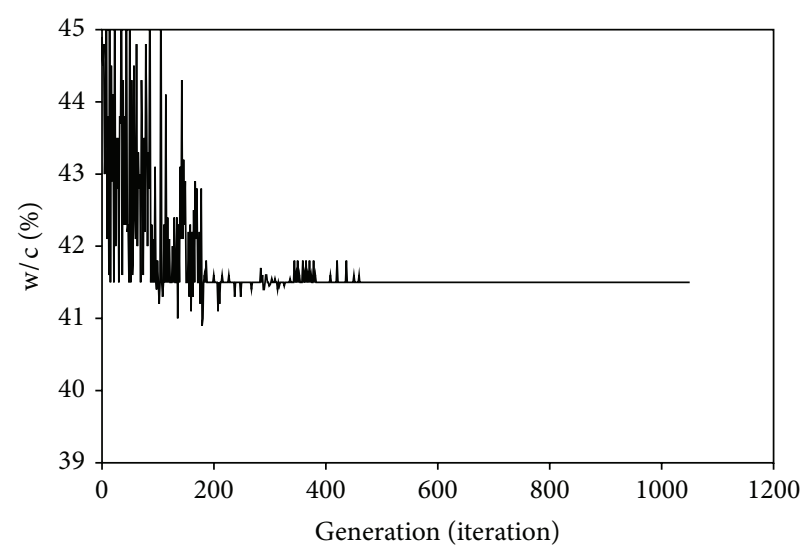

(d) $\mathrm{w} / \mathrm{c}$ ratio

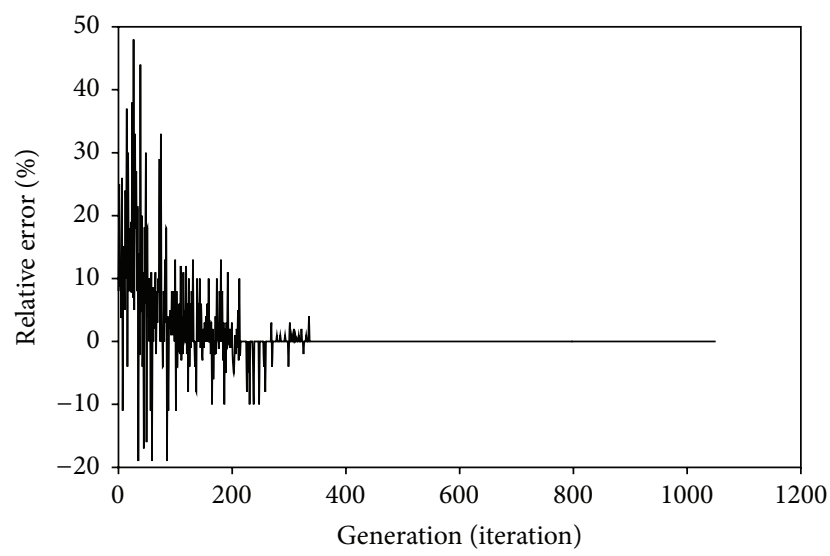

(e) Relative error

FIGURE 7: Simulated process through GA (w/c 0.42 and R.H. 10\%).

in underground site. Extremely high $\mathrm{CO}_{2}$ concentration of $2,700 \mathrm{ppm}$ is assumed for A structure and $980 \mathrm{ppm}$ which is normal condition in underground structure is assumed for B structure. Durability limit state is determined as the condition when carbonation proceeds to steel location [23,
27]. For governing equation, mesolevel equation from $\mathrm{CEB}$ [23] is adopted as follows:

$$
d_{C}=\sqrt{2 k_{1} k_{2} k_{3} \Delta c} \cdot \sqrt{\frac{D_{\mathrm{CO}_{2}} t}{a}}\left(\frac{t_{0}}{t}\right)^{n},
$$


TABLE 8: Design parameters for carbonation design.

(a)

\begin{tabular}{|c|c|c|c|c|}
\hline Type & & Structure A & & Structure B \\
\hline Intended service life (year) & & 75 & & 100 \\
\hline Design cover depth (mm) & & 50 & & 30 \\
\hline Extoriorcondition & & R.H.: $65 \%$ & & R.H: 75\% \\
\hline Exterior condition & & Temp.: $12.7^{\circ} \mathrm{C}$ & & Temp.: $22^{\circ} \mathrm{C}$ \\
\hline $\mathrm{CO}_{2}$ concentration $(\mathrm{ppm})$ & & 2,700 & & 980 \\
\hline Durability limit state & & \multicolumn{3}{|c|}{ carbonation depth $=$ cover depth } \\
\hline \multicolumn{5}{|c|}{ (b) } \\
\hline $\begin{array}{l}\text { Assumed cement } \\
\text { weight }\left(\mathrm{kg} / \mathrm{m}^{3}\right)\end{array}$ & 300 & 330 & 335 & 370 \\
\hline $\begin{array}{l}\text { Intended diffusion } \\
\text { coefficient } \times 10^{-11} \\
\left(\mathrm{~m}^{2} / \mathrm{sec}\right)\end{array}$ & 1,742 & 1,916 & 1,248 & 1,378 \\
\hline
\end{tabular}

TABLE 9: Mixture design through proposed GA technique.

\begin{tabular}{|c|c|c|c|c|c|c|c|}
\hline & Case & Intended diffusion coefficient $\left(10^{-11} \mathrm{~m}^{2} / \mathrm{sec}\right)$ & $\mathrm{w} / \mathrm{c}(\%)$ & Cement $\left(\mathrm{kg} / \mathrm{m}^{3}\right)$ & S/a (\%) & Coarse aggregate $\left(\mathrm{kg} / \mathrm{m}^{3}\right)$ & R.H. (\%) \\
\hline \multirow{2}{*}{ A } & Structure A & \multirow{2}{*}{1,742} & 42.3 & 300 & 38.4 & 1191.0 & 65 \\
\hline & Input range & & $42-58$ & $300-300$ & $37-43$ & $800-1,200$ & $65-65$ \\
\hline \multirow{2}{*}{ B } & Structure A & \multirow{2}{*}{1,916} & 52.7 & 330 & 38.1 & 960.2 & 65 \\
\hline & Input range & & $42-58$ & $330-330$ & $37-43$ & $800-1,200$ & $65-65$ \\
\hline \multirow{2}{*}{$\mathrm{C}$} & Structure B & \multirow{2}{*}{1,248} & 49.6 & 335 & 41.2 & 1172.8 & 75 \\
\hline & Input range & & $42-58$ & $335-335$ & $37-43$ & $900-1,200$ & $75-75$ \\
\hline \multirow{2}{*}{ D } & Structure B & \multirow{2}{*}{1,378} & 51.4 & 370 & 40.1 & 875.3 & 75 \\
\hline & Input range & & $42-58$ & $370-370$ & $37-43$ & $800-1,200$ & $75-75$ \\
\hline
\end{tabular}

The bold numbers are results from GA.

where $d_{C}$ is carbonation depth (mm), $k_{1}$ is constant for local condition, $k_{2}$ is constant for curing condition, $k_{3}$ is constant for locally different w/c ratio, $\Delta c$ is $\mathrm{CO}_{2}$ concentration $\left(\mathrm{kg} / \mathrm{m}^{3}\right), D_{\mathrm{CO}_{2}}$ is $\mathrm{CO}_{2}$ diffusion coefficient $\left(\mathrm{m}^{2} / \mathrm{sec}\right), a$ is carbonation reaction function with hydrate amount, $n$ is constant for cyclic drying and wetting, $t_{0}$ is reference time ( 1 year), and $t$ is exposed period (year).

For considering the effect of temperature on carbonation, a parameter like (4) is considered [4]. Consider

$$
f(T)=D_{\text {ref }} \exp \left[\frac{U}{R}\left(\frac{1}{T_{\text {ref }}}-\frac{1}{T}\right)\right],
$$

where $D_{\text {ref }}$ is referential $\mathrm{CO}_{2}$ diffusion coefficient, $U$ is activation energy of $\mathrm{CO}_{2}(8500 \mathrm{Cal} / \mathrm{mol} \cdot \mathrm{K}), R$ is universal gas constant, $T_{\text {ref }}$ is reference temperature $(298 \mathrm{~K})$, and $T$ is exterior temperature $(\mathrm{K})$.

In (3), the target structure is assumed to have normal construction level and to be sheltered from rain and $k_{1}, k_{2}$, $k_{3}$, and $n$ can be assumed as 1.0 and 0.0 , respectively [23]. Considering the temperature parameter, (3) can be written as follows:

$$
d_{C}=\sqrt{2 \Delta c} \cdot \sqrt{\frac{D_{\mathrm{CO}_{2}} f(T)}{a} t},
$$

where $a$ can be expressed as follows (CEB 1997):

$$
a=0.75 \cdot C \cdot \mathrm{CaO} \cdot \alpha_{\mathrm{H}} \frac{M_{\mathrm{CO}_{2}}}{M_{\mathrm{CaO}}},
$$

where $C$ is unit content of cement $\left(\mathrm{kg} / \mathrm{m}^{3}\right), \mathrm{CaO}$ is content of $\mathrm{CaO}$ (calcium oxide, 0.65$), \alpha_{H}$ is hydration rate $(0.85)$, and $M$ is molar weight $\left(\mathrm{CO}_{2}: 44 \mathrm{~g} / \mathrm{mol}, \mathrm{CaO}: 56 \mathrm{~g} / \mathrm{mol}\right)$.

In (5), $\Delta c, a, t$, and $T$ are given by design parameter. Considering the durability limit state (carbonation depth $=$ cover depth), intended diffusion coefficient can be calculated.

The design parameters above are summarized in Table 8.

In (5), two unknown variables exist so that unit content of cement is assumed referring to conventional mix proportions in domestic condition [25]. Four different contents of cement are assumed and the related intended diffusion coefficients are derived through (5).

4.2.2. Derivation of Optimum Mix Proportions. In this section, optimum mix proportions are derived through GA technique. The fitness function of (2) is utilized for obtaining mix components with fixed R.H. and cement content.

The results of mix proportions are listed in Table 9. 
As shown in Table 9, intended diffusion coefficient and unit cement content are given and mix proportions for concrete can be obtained through GA technique. When this technique is applied, convergence of relative error to 0.0 should be checked.

In this paper, fitness function for $\mathrm{CO}_{2}$ diffusion coefficient is derived based on the previous test results, and then concrete mix design is proposed through GA technique. However, this technique is only for OPC concrete mix design and has limitation of range for mix proportion. The applicable ranges of unit content of cement and w/c ratio are $277 \mathrm{~kg} / \mathrm{m}^{3} \sim 425 \mathrm{~kg} / \mathrm{m}^{3}$ and $0.42 \sim 0.58$ since both the fitness function and the process for generating each mix proportion are governed by test dataset which is previously adopted.

With more data-set containing $\mathrm{CO}_{2}$ diffusion coefficient and an accurate fitness function, the proposed technique would be much improved. This technique is applied for mix proportion of concrete under carbonation. With similar procedures, this can be applied to generation of mix proportions which can guarantee the service life of RC structures exposed to different deteriorations like chloride attack, freezing and thawing action, and sulfate attack.

\section{Concluding Remark}

The conclusions on concrete mix optimization technique for service life of RC structures under carbonation using genetic algorithm are as follows.

(1) Based on the previous experimental results, fitness function for $\mathrm{CO}_{2}$ diffusion coefficient containing the variables like mix proportions (w/c ratio, unit content of cement, sand/aggregate ratio, and unit content of coarse aggregate) and R.H. (relative humidity) is derived. Through consideration of the parameters of R.H., variation of relative errors decreases.

(2) Through GA technique, three concrete mix proportions are simulated for verification. The simulated results provide below $10.1 \%$ of relative errors for each mix component such as w/c ratio, unit content of cement, sand ratio to total aggregate, and unit content of coarse aggregate.

(3) Assuming the exposure conditions of carbonation and design parameters, intended diffusion coefficients are determined and optimum concrete mix proportions which satisfy intended service life are obtained through GA technique. The results from this study are only applicable to OPC concrete. If data-set with mineral and chemical admixtures is prepared, this technique can be applied more widely to durability design for RC structures under carbonation.

\section{Conflict of Interests}

The authors declare that there is no conflict of interests regarding the publication of this paper.

\section{Acknowledgment}

This research was supported by a grant (Code 11-Technology Innovation-F04) from Construction Technology Research Program funded by Ministry of Land, Infrastructure and Transport.

\section{References}

[1] K. Kobayashi and Y. Uno, "Mechanism of carbonation of concrete," Japan Society of Civil Engineers, vol. 1, no. 1, pp. 139$151,1990$.

[2] I. Izumi, D. Kita, and H. Maeda, Carbonation, Kibodang Publication, 1986.

[3] T. Ishida and K. Maekawa, "Modeling of PH profile in pore water based on mass transport and chemical equilibrium theory," Japan Society of Civil Engineers, vol. 1, no. 37, pp. 151166, 2001.

[4] T. Saeki, H. Ohga, and S. Nagataki, "Change in micro-structure of concrete due to carbonation," Japan Society of Civil Engineers, vol. 1, no. 18, pp. 1-11, 1991.

[5] CEB, Durable Concrete Structures-Design Guide, Thomas Telford, London, UK, 2nd edition, 1992.

[6] V. G. Papadakis, C. G. Vayenas, and M. N. Fardis, "Physical and chemical characteristics affecting the durability of concrete," ACI Materials Journal, vol. 88, no. 2, pp. 186-196, 1991.

[7] T. Ishida and K. Maekawa, "Modeling of durability performance of cementitious materials and structures based on thermohygro physics," in Proceedings of the 2nd International RILEM Workshop on Life Prediction and Aging Management of Concrete Structures, 2003.

[8] F. P. Glasser, J. Marchand, and E. Samson, "Durability of concrete-degradation phenomena involving detrimental chemical reactions," Cement and Concrete Research, vol. 38, no. 2, pp. 226-246, 2008.

[9] S. J. Kwon, S. S. Park, S. H. Nam, and H. J. Cho, "A study on survey of carbonation for sound, cracked, and joint concrete in RC column in metropolitan city," Journal of the Korea Institute For Structural Maintenance and Inspection, vol. 11, no. 3, pp. 116122, 2007.

[10] H. W. Song, S. J. Kwon, K. J. Byun, and C. K. Park, "Predicting carbonation in early-aged cracked concrete," Cement and Concrete Research, vol. 36, no. 5, pp. 979-989, 2006.

[11] O. B. Isgor and A. G. Razaqpur, "Finite element modeling of coupled heat transfer, moisture transport and carbonation processes in concrete structures," Cement and Concrete Composites, vol. 26, no. 1, pp. 57-73, 2004.

[12] S. J. Kwon and U. J. Na, "Prediction of durability for RC column with crack and joint under carbonation based on probabilistic approach," International Journal of Concrete Structures and Materials, vol. 5, no. 1, pp. 11-18, 2011.

[13] Y. F. Houst and F. H. Wittmann, "Influence of porosity and water content on the diffusivity of $\mathrm{CO}_{2}$ and $\mathrm{O}_{2}$ through hydrated cement paste," Cement and Concrete Research, vol. 24, no. 6, pp. 1165-1176, 1994.

[14] S. H. Jung, M. K. Lee, and B. H. Oh, "Measurement device and characteristics of diffusion coefficient of carbon dioxide in concrete," ACI Materials Journal, vol. 108, no. 6, pp. 589-595, 2011. 
[15] S. H. Jung, Diffusivity of carbon dioxide and carbonation in concrete through development of gas diffusion measuring system [Ph.D. thesis], Deptartment of Civil Engineering, Seoul National University, Seoul, Republic of Korea, 2002.

[16] S. J. Kwon and H. W. Song, "Analysis of carbonation behavior in concrete using neural network algorithm and carbonation modeling," Cement and Concrete Research, vol. 40, no. 1, pp. 119$127,2010$.

[17] I. C. Yeh, "Computer-aided design for optimum concrete mixtures," Cement and Concrete Composites, vol. 29, no. 3, pp. 193-202, 2007.

[18] C. H. Lim, Y. S. Yoon, and J. H. Kim, "Genetic algorithm in mix proportioning of high-performance concrete," Cement and Concrete Research, vol. 34, no. 3, pp. 409-420, 2004.

[19] S. J. Kwon and S. C. Kim, "Concrete mix design for service life of RC structures exposed to chloride attack," Computers and Concrete, vol. 10, no. 1, pp. 687-607, 2012.

[20] E. Cantú-Paz and D. E. Goldberg, "Efficient parallel genetic algorithms: theory and practice," Computer Methods in Applied Mechanics and Engineering, vol. 186, no. 2-4, pp. 221-238, 2000.

[21] D. E. Goldberg, Genetic Algorithms in Search, Optimization and Machine Learning, Addison-Welsley, Reading, Mass, USA, 1989.

[22] Y. Abe, "Result of reference review on crack width effect to carbonation of concrete," in Proceedings of the Symposium on Rehabilitation of Concrete Structures, 1999.

[23] CEB Task Group 5.1, 5.2, New Approach to Durability Design, CEB, Sprint-Druck, Stuttgart, Germany, pp. 53-62, May 1997.

[24] KICT-Korea Institute of Construction Technology, "Durability improvement of concrete with sea/normal sand," Tech. Rep. R\&D/97-0001, section 1-3, Bon Press, Seoul, Republic of Korea, 1997.

[25] KSCE-Korea Society of Civil Engineering, "Study on durability improvement for underground structure," Tech. Rep., Seoul Metropolitan Government Office of Subway Construction, KSCE Press, Seoul, Republic of Korea, 1999.

[26] KCI-Korea Concrete Institute, Concrete SpecificationDurability, 2004.

[27] RILEM, "Durability design of concrete structures," Report of RILEM Technical Committee 130-CSL, E\&FN, 1994, pp. 75-78.

[28] JSCE-Concrete Committee, Standard Specification for Concrete Structures, 2002.

[29] Mathworks, Genetic Algorithm and Direct Search Toolbox 2, User's Guide, 2007. 

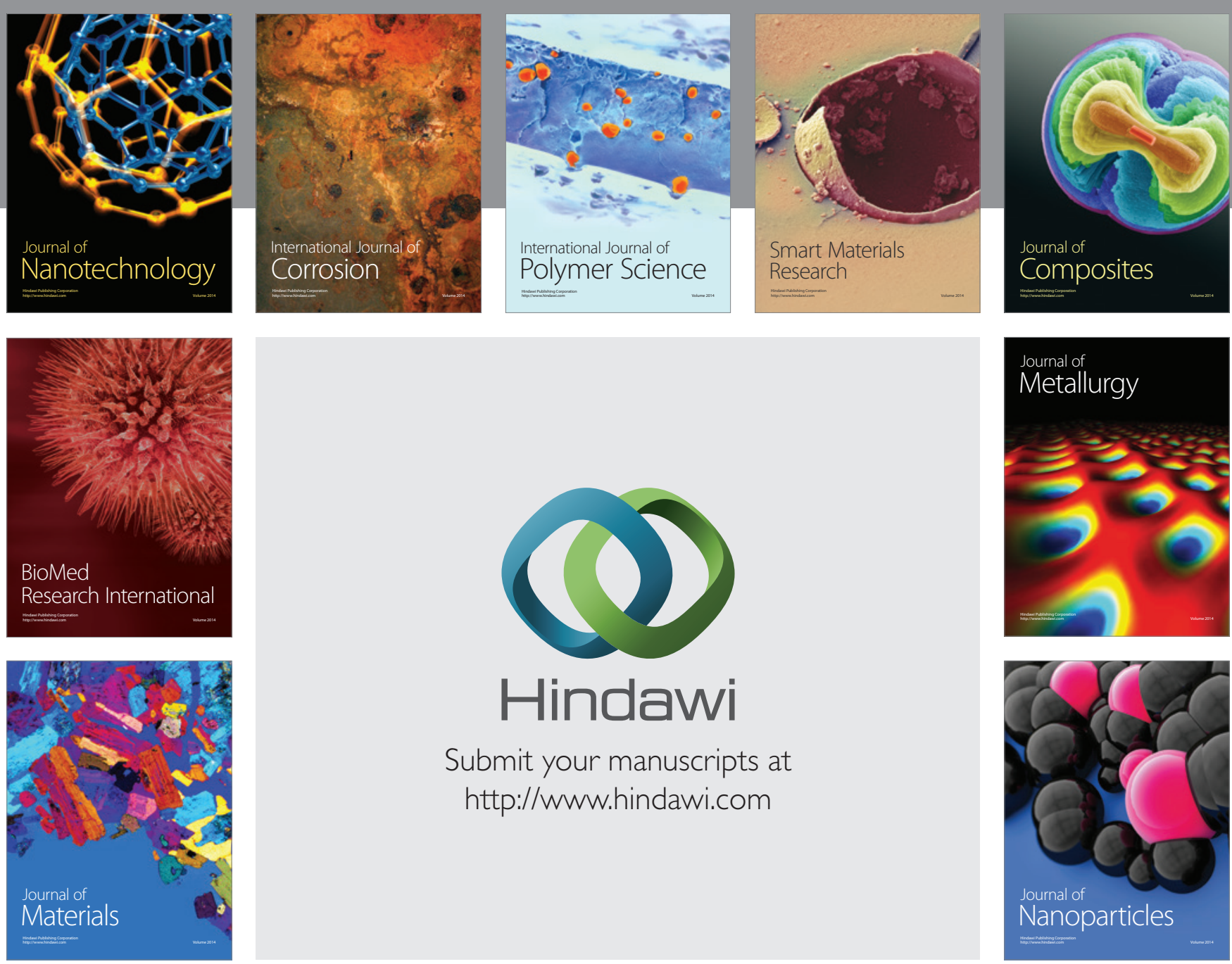

Submit your manuscripts at http://www.hindawi.com
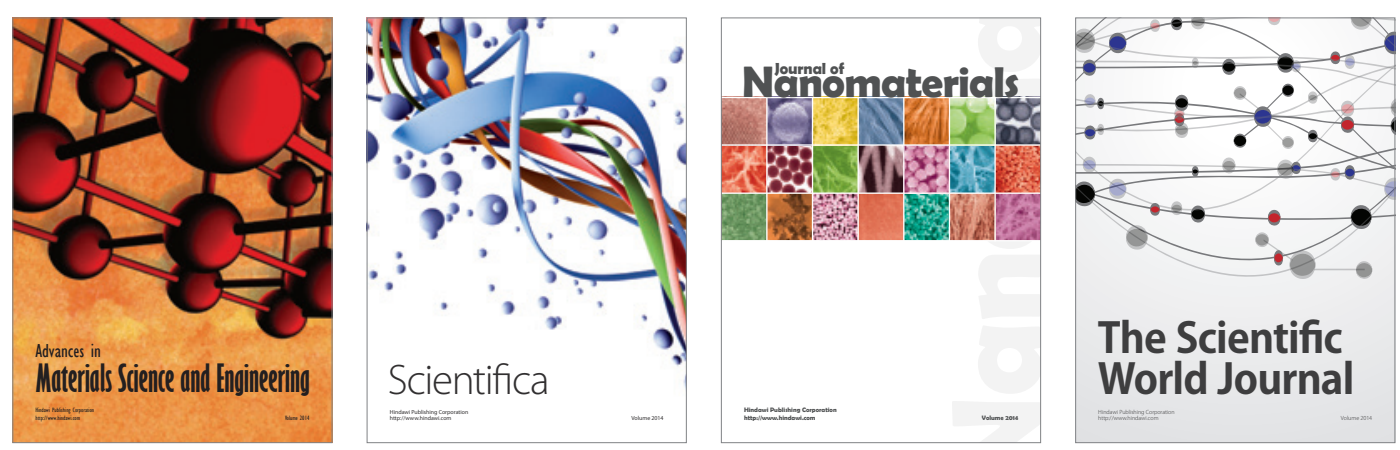

\section{The Scientific World Journal}
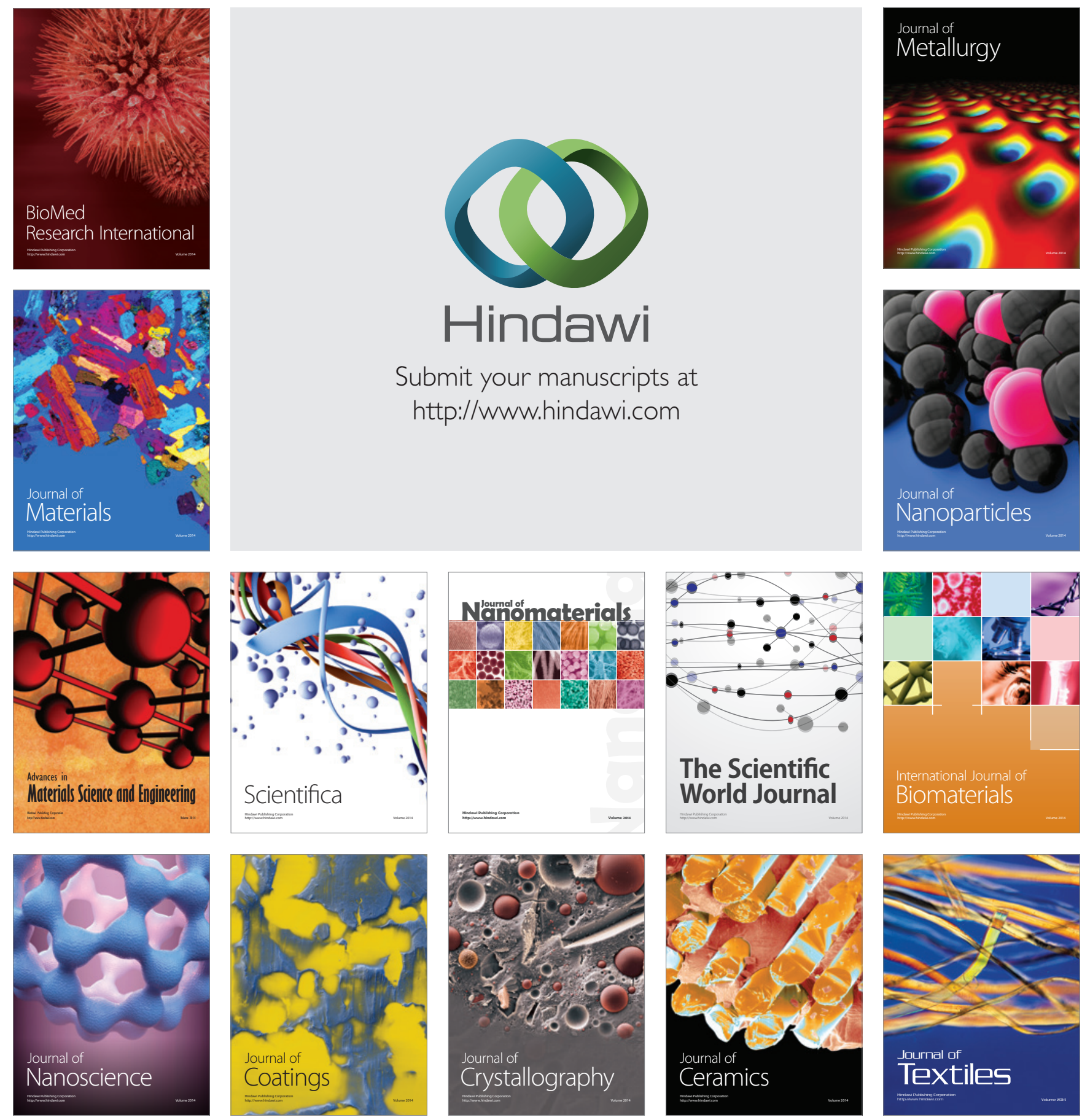